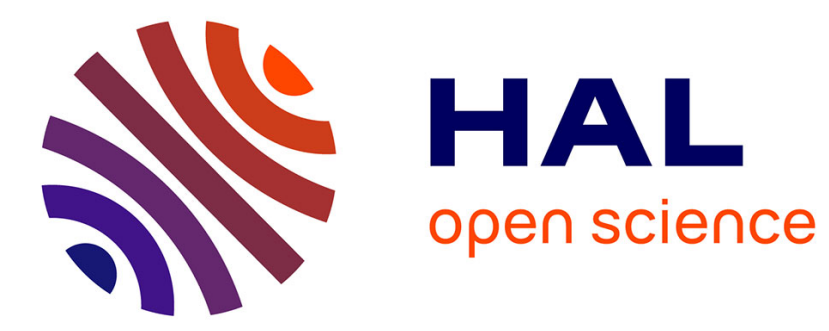

\title{
The importance of crustal structure in explaining the observed uncertainties in ground motion estimation
}

\author{
John Douglas, Hideo Aochi, Peter Suhadolc, Giovanni Costa
}

\section{To cite this version:}

John Douglas, Hideo Aochi, Peter Suhadolc, Giovanni Costa. The importance of crustal structure in explaining the observed uncertainties in ground motion estimation. Bulletin of Earthquake Engineering, 2007, 5 (1), pp.17-26. 10.1007/s10518-006-9017-y . hal-00557603

\section{HAL Id: hal-00557603 https://hal-brgm.archives-ouvertes.fr/hal-00557603}

Submitted on 19 Jan 2011

HAL is a multi-disciplinary open access archive for the deposit and dissemination of scientific research documents, whether they are published or not. The documents may come from teaching and research institutions in France or abroad, or from public or private research centers.
L'archive ouverte pluridisciplinaire HAL, est destinée au dépôt et à la diffusion de documents scientifiques de niveau recherche, publiés ou non, émanant des établissements d'enseignement et de recherche français ou étrangers, des laboratoires publics ou privés. 


\title{
The importance of crustal structure in explaining the observed uncertainties in ground motion estimation Short communication
}

\author{
John Douglas, Hideo Aochi \\ ARN/RIS, BRGM, 3 avenue C. Guillemin, BP 36009, 45060 Orléans Cedex 2, France. \\ Peter Suhadolc and Giovanni Costa \\ Dipartimento di Scienze della Terra, University of Trieste, via E. Weiss 1, 34127 Trieste, Italy.
}

June 5, 2006

\begin{abstract}
In this short article, the possible reduction in the standard deviation of empirical ground motion estimation equations through the modelling of the effect of crustal structure is assessed through the use of ground-motion simulations. Simulations are computed for different source-to-site distances, focal depths, focal mechanisms and for crustal models of the Pyrenees, the western Alps and the upper Rhine Graben. Through the method of equivalent hypocentral distance introduced by Douglas et al. [2004] to model the effect of crustal structure in empirical equations, the scatter associated with such equations derived using these simulated data could be reduced to zero if real-to-equivalent hypocentral distance mapping functions were derived for every combination of mechanism, depth and crustal structure present in the simulated dataset. This is, obviously, impractical. The relative importance of each parameter in affecting the decay of ground motions is assessed here. It is found that variation in focal depth is generally more important than the effect of crustal structure when deriving the real-to-equivalent hypocentral distance mapping functions. In addition, mechanism and magnitude do not have an important impact on the decay rate.
\end{abstract}

\section{Introduction}

Douglas et al. [2004] introduce a new distance metric that seeks to capture in empirical ground motion estimation equations (GMEEs) the effect on the decay rate of the layered structure of the crust. This layered structure leads to a much more complex decay of ground motions with distance than is currently captured in any GMEE. Also the differences in crustal structures between regions cause correspondingly different decay rates, which could be responsible for 
some of the variability in observed ground motions. This variability is shown by the large aleatory uncertainties associated with GMEEs (measured by their standard deviations), which are not significantly decreasing with time despite increasing data and complexity of analysis [e.g. Douglas, 2003].

In the method of Douglas et al. [2004], the real hypocentral distance $\left(r_{\text {real }}\right)$ is converted to the equivalent hypocentral distance $\left(r_{\text {equivalent }}\right)$ that would experience the same amplitude decay as a station on a homogenous crust. For each strong-motion record used, a theoretical decay curve is defined through ground motion simulations for the region where the earthquake occurred. $r_{\text {real }}$ is then mapped to $r_{\text {equivalent }}$ and $r_{\text {equivalent }}$ is used for the regression analysis, in which the geometrical decay is constrained to $1 / r$. Data from regions with different crustal structures can then be combined since $r_{\text {equivalent }}$ incorporates the effect of crustal structure, whereas $r_{\text {real }}$ does not. The advantage of this method is that a complex form of the equation is not needed; the effect of crustal structure is handled by using a better distance metric. Also it removes the need to use simple functional forms to handle increased amplitudes due to reflections off the Mohorovičić discontinuity or a change to surface-wave decay, since they are implicitly handled by the distance metric.

To evaluate their technique, Douglas et al. [2004] conducted a small test based on observed data from Umbria-Marche and south Iceland, which are areas with considerably different crustal structures and hence theoretically different decay rates. The data were combined together with and without correction for the effect of the crust and simple GMEEs were derived. Disappointingly, and surprisingly, the standard deviations of the equations derived having corrected for the different effects of the crust in the two regions were higher than those of the equations derived having neglected crustal effects.

There are two possible reasons for this disappointing result. Firstly, the crustal structure models of the wave velocities, densities and $\mathrm{Q}$ values for the two regions were not completely appropriate. It is likely that this is an important factor since there is still uncertainty in the true structure of the crust for the two examined regions, which is demonstrated by the wide dispersion in the three crustal structures for south Iceland (see Figure 4 of Douglas et al. [2004]). In addition, the values of Q used for the computation of the synthetics for the two regions were taken from global relations connecting velocity and anelastic attenuation and therefore probably are not completely appropriate. The second possible reason for no reduction in the scatter is that the real-to-equivalent hypocentral distance mapping functions used were for a specific magnitude $\left(M_{w} 5\right)$, focal depth $(5 \mathrm{~km})$, azimuth $\left(22.5^{\circ}\right)$ and focal mechanism (pure strike-slip) whereas the observational data used were from earthquakes with differing magnitudes, depths and mechanisms and from stations at different azimuths. All of these 
additional factors have an effect on the decay rate of ground motions, particularly the focal depth (see Figure 9 of Douglas et al. [2004]). Therefore the distance mapping functions were not wholly correct for all the examined data. Possibly the effect of one or more of the ignored factors (magnitude, depth, mechanism or azimuth) on the decay is more important than the difference in the decay rate caused by the differing crusts in the two regions.

If real-to-equivalent hypocentral distance mapping functions were derived for all combinations of magnitude, depth, mechanism and azimuth present in the observed data set using a highly accurate model of the crustal structure then the scatter caused by crustal effects could be reduced to practically zero. Obviously computing individual mapping functions for every record is impractical. Hence the purpose of this short article is to rank the importance of different factors: magnitude, mechanism, depth and crustal structure, affecting the decay of ground motions.

Ground motions at distances greater than about $20 \mathrm{~km}$ from small and moderate earthquakes are unlikely to cause damage to engineering structures [e.g. Martínez-Pereira and Bommer, 1998] hence it could be argued that an investigation of the effect of crustal structure, which is most likely to only be important at long distances, is not useful. However, the standard deviations of ground motion estimation equations are mainly based on records from intermediate and great distances since these are more common than near-field records. The implicit assumption, therefore, made is that the scatter at moderate and large distances is similar to that at short distances where ground motions are damaging. Ambraseys and Douglas [2003] show using a set of data from distances of $15 \mathrm{~km}$ or less that this assumption is valid, since they found similar standard deviations for their near-field GMEEs to those of GMEEs derived using data from moderate and large distances. Hence it is important to understand the cause of the scatter at moderate and large distances even though such motions are unlikely to be damaging to engineering structures. Also modelling the variation in ground motions due to crustal structure would allow more accurate investigation of other effects affecting ground motions.

\section{Selected regions and crustal structure models}

Three regions of metropolitan France: Pyrenees, upper Rhine Graben and the western Alps, were selected for study. Crustal velocity structures for these regions could be obtained from the global model CRUST2.0 [Laske et al., 2005] or from the European model EurID [Du et al., 1998]. However, it was shown in Douglas et al. [2004] that a better fit between synthetic and observed accelerograms is obtained by using local crustal velocity structure models. Therefore in this study only models that have been derived for the specific regions studied are used. 
The following crustal velocity structure models are adopted: for the Alps, Costa et al. [1993] at 45.40N-6.11E; for the Pyrenees, Souriau and Granet [1995] at 43.05N-0.04W; and for the upper Rhine graben, Lopes Cardozo [2003] at 47.76N-7.25E. Unfortunately, the profiles chosen for the Pyrenees and the upper Rhine Graben do not provide information on the velocities in the top few kilometres because of the type of data used for their derivations. Therefore, in order to include realistic near-surface velocities the generic rock profiles suggested by Boore and Joyner [1997] were appended to the top of the adopted structures. By comparing the structure for the upper Rhine graben to the two generic profiles provided by Boore and Joyner [1997] at depths greater than $2 \mathrm{~km}$ it was decided to append their 'generic rock site' profile (their Table 1) since this closely matches the adopted profile at common depths. In the finite difference method (FDM) adopted, the lowest P- and S-wave velocities used are $1.7 \mathrm{kms}^{-1}$ and $1.0 \mathrm{kms}^{-1}$ respectively, for the grid at the ground surface. For the Pyrenees the velocities of the 'generic very hard rock site' of Boore and Joyner [1997] (their Table 2) were found to provide a close match at common depths, therefore they were appended. These findings are consistent with the statement of Boore and Joyner [1997] that sites with their 'very hard rock site profile' are found in areas where glaciers have scoured the weathered and cracked nearsurface materials; such areas are common in the Pyrenees whereas they are less common in the Rhine graben region. Figure 1 displays a comparison between the crustal models used.

[Figure 1 about here.]

Published density estimates for the chosen regions are not common. Therefore the commonlyadopted relation of Gardner et al. [1974]: $\rho=1.741 V_{p}^{0.25}$, where $V_{p}$ is P-wave velocity in $\mathrm{km} / \mathrm{s}$ and $\rho$ is density in $\mathrm{g} / \mathrm{cm}^{3}$, was adopted. Minor changes in the density values will not significantly affect the results. $Q=300$ is assumed for the entire medium, but, in fact, this leads to no significant anelastic attenuation in the simulations.

\section{Ground motion simulations}

To simulate wave propagation in the different crustal models, a standard staggered FDM, which is fourth order in space and second order in time [Levander, 1988, Olsen, 1994], is used. This was previously used in the second author's simulations for a finite fault source model [Aochi and Madariaga, 2003]. A time-variable double-couple point source (see Figure 2) with a strike of $0^{\circ}$ is introduced, using the technique of Olsen [1994] and Graves [1996], at the origin of the model region. The largest earthquake simulated is $M_{w} 5.5$ hence the point source approximation is not too great. The mechanism-independent equation of Wells and Coppersmith [1994] for subsurface fault length was used to estimate the source duration assuming a rupture velocity of 
$2.5 \mathrm{~km} / \mathrm{s}$, giving durations of $0.66,1.30$ and $2.55 \mathrm{~s}$ for the source-time functions of earthquakes of $M_{w} 4.5,5.0$ and 5.5 , respectively.

Ground motions are calculated within a halfspace $(-55-55 \mathrm{~km}$ by $-12.5-55 \mathrm{~km}$ by $-43.75-$ $0 \mathrm{~km}$ ) at spatial grid points with $250 \mathrm{~m}$ spacing using a time step of $0.01 \mathrm{~s}$, which is sufficient for the assumed source-time function and the wave velocities in the crustal models $(200 \mathrm{~m}$ and $0.01 \mathrm{~s}$ are used for the upper Rhine Graben, which has a lower velocity layer near the surface). Synthetic seismograms are calculated at different epicentral distances from 0 to $55 \mathrm{~km}$ at stations located every $8^{\circ}$ in azimuth. In order to avoid the extreme effect of a nodal plane (which is rarely observed), stations are not located in the direction of, or perpendicular to, the fault strike. Figure 2 shows the station spacing.

[Figure 2 about here.]

Because the assumed source model (point source with a simple smooth time function) poorly simulates the high frequency $(>3 \mathrm{~Hz})$ content of the motions it was decided to study the decay of peak ground velocity (PGV). In addition, the geometric mean of the PGV of the two horizontal components (orientated north-south and east-west in the simulations) is studied to conform with the definition commonly adopted in empirical studies [e.g Campbell, 1997]. The average of the PGVs at each distance in the upper semi-circle of the simulation space is calculated to remove the effect of azimuth, which although theoretically important, is not generally found to be observed in real earthquake ground motions. The decay rate within the simulations was found not to depend strongly on azimuth - the azimuth only strongly effects the amplitude.

\section{Results}

Figure 3 compares the simulated PGVs for a $M_{w} 5.0$ earthquake at a depth of $5 \mathrm{~km}$ using the Alpine structure for three focal mechanisms: dip-slip faulting with rake $(\lambda)$ of $-90^{\circ}$ and dips $(\delta)$ of 45 and $60^{\circ}$ (results for $\delta=30^{\circ}$ are identical to those for $60^{\circ}$ ) and strike-slip faulting with $\lambda=0^{\circ}$ and $\delta=90^{\circ}$. This figure shows that although the mechanism slightly affects the amplitude of the ground motions due to differences in average radiation pattern [Boore and Boatwright, 1984] the decay rate of PGV is not strongly affected. Similarly for the other two regions the decay rate is not strongly affected by mechanism. This means that real-to-equivalent mapping functions do not need to be developed for specific mechanisms and the usual method of magnitude- and distance-independent factors to model the observed differences in ground motions due to mechanism [Bommer et al., 2003] can be used. 
[Figure 3 about here.]

Figure 4 compares the simulated PGVs for normal earthquakes of $M_{w} 4.5,5.0$ and 5.5 at a depth of $10 \mathrm{~km}$ using the Alpine structure showing that, although the magnitude strongly affects the amplitude of the ground motions, the decay rates are similar. Like for the Alps, simulations using the structures for the Pyrenees and the Rhine region do not show a strong dependence of decay rate on magnitude. Therefore real-to-equivalent mapping functions do not need to be developed for different magnitudes and the current practice of modelling magnitude dependence of ground motions through the functional form and regression can be retained.

[Figure 4 about here.]

Figure 5 compares simulated PGV values for dip-slip $\left(\delta=45^{\circ}\right)$ earthquakes in all three structures at varying depths. The large variation in the simulated PGVs is noticeable. In particular, the PGVs show inter-region differences for the same focal depth (e.g. compare the curves for a focal depth of $5 \mathrm{~km}$ ) and intra-region differences for different focal depths (e.g. compare the curves for the western Alps region). The decay curves for the Pyrenees structure are smooth and they do not show a strong dependence on focal depth since the Pyrenean crustal structure does not feature any significant velocity contrasts, which can reflect and refract seismic waves, until a depth of $35 \mathrm{~km}$. Also shown are the PGVs predicted by the GMEE of Campbell [1997] for a $M_{w} 5.0$ earthquake, showing that the simulated PGV values are similar to those predicted by equations based on observed strong-motion data although, in general, two-to-three times higher, which could be due to a source-time function that is too rich in low frequencies compared to the standard $\omega^{2}$ spectrum. The amplitude of the simulated ground motions can be reduced by assuming a slower rupture velocity, and thus a longer duration, with an corresponding reduction in the amplitude of the source-time function.

[Figure 5 about here.]

Figure 5 shows that near-source PGVs strongly depend on the focal depth and crustal structure and therefore it is not appropriate to derive the real-to-equivalent mapping functions individually for each structure and depth since this would make the implicit assumption that near-source ground motions for all regions and depths were identical (see p. 93 of Douglas et al. [2004]). Hence it was decided to normalise all the real-to-equivalent mapping functions to the simulated PGV value at an epicentral distance of $2 \mathrm{~km}\left(r_{\text {real }}=\sqrt{5^{2}+2^{2}}=5.4 \mathrm{~km}\right)$ for the Rhine structure for a focal depth of $5 \mathrm{~km}$. This choice means that the observed differences in near-source ground motions will be incorporated within the mapping functions. Thus in this study, $r_{\text {equivalent }}$ are calculated via the mapping function: $r_{\text {equivalent }}=5.4 y^{\prime}(5.4 \mathrm{~km}) / y\left(r_{\text {real }}\right)$ 
where $y^{\prime}(5.4 \mathrm{~km})$ is the simulated PGV value at $r_{\text {real }}=5.4 \mathrm{~km}$ for the Rhine structure for a focal depth of $5 \mathrm{~km}$ and $y\left(r_{\text {real }}\right)$ is the simulated PGV at a real hypocentral distance of $r_{\text {real }}$. Figure 6 shows the computed real-to-equivalent distance mappings for the three regions for each of the three depths for a $M_{w} 5.0$ dip-slip $\left(\delta=45^{\circ}\right)$ earthquake. This figure shows a large variation in the mapping functions between regions and between depths, e.g. for the Rhine structure for a focal depth of $5 \mathrm{~km}$ at $r_{\text {real }}=50 \mathrm{~km} r_{\text {equivalent }} \approx 80 \mathrm{~km}$ whereas for the Pyrenees structure and the same depth it equals about $200 \mathrm{~km}$. These variations in the mapping functions reflect differences in the simulated decay rates shown in Figure 5.

[Figure 6 about here.]

In order to assess the ability of the equivalent hypocentral distance technique to lead to a reduction in ground motion scatter due to regional crustal differences, the standard deviation of the mean real-to-equivalent hypocentral distance mapping functions for a region (i.e. neglecting focal depth) and for a focal depth (i.e. neglecting region) were computed. These standard deviations measure the importance of assuming either a single mapping function for a region (regardless of focal depth) or a single mapping function for a focal depth (regardless of region). Figure 7 shows these computed standard deviations with respect to real hypocentral distance. It shows that the standard deviations of the equivalent hypocentral distance mapping functions computed with respect to the three regions are, in general, higher than the standard deviations computed with respect to the three focal depths. This shows that focal depth within a given region is more important than regional differences in crustal structure for a given focal depth. This is thought to be due to similarities in the crustal structural models of the three regions at depths around $10 \mathrm{~km}$ (see Figure 1). On the other hand, for shallow and deep earthquakes ( $h=5$ and $15 \mathrm{~km}$ ) the effect of region is more important than for $h=10 \mathrm{~km}$ because the three crustal models are significantly different around these depths.

[Figure 7 about here.]

\section{Conclusion}

In this brief article, a number of ground motion simulations have been conducted in order to assess the utility of the equivalent hypocentral distance technique introduced by Douglas et al. [2004] to capture the possible regional dependence of ground motions due to differences in crustal structure. For the three regions studied: the western Alps, the Pyrenees and the upper Rhine Graben, it has been found that focal depth is more important in explaining the variation in decay of the simulated ground motions than differing crustal structures although this should 
be verified for other regions. Hence, in order to use the technique of equivalent hypocentral distance in practice, real-to-equivalent mapping functions need to be derived for different focal depths and different crustal structures. The modelling of other effects such as focal mechanism and magnitude can be accounted for by the functional form and regression analysis. This is, in fact, better than trying to model them through the distance metric since the physical basis of the observed dependence on focal mechanism and magnitude is not yet clear and hence it is appropriate to allow the observed data to constrain their effects in the ground-motion model. Recent observational results [e.g. Ambraseys et al., 2005] show that the decay rate of ground motions is magnitude dependent - ground motions from larger earthquakes decay less rapidly than those from small earthquakes. This was not observed here where simulations were only conducted up to $M_{w} 5.5$, so the results reported here may not be able to be extrapolated to larger magnitudes.

\section{Acknowledgements}

This study was funded by internal BRGM research projects. Financial contributions from INTERREG IIIB Alpine Space project SISMOVALP and ProCiv-INGV 2004-06 Executive project S4: 'Stima dello scuotimento in tempo reale e quasi-reale per terremoti significativi in territorio nazionale' are also acknowledged. We thank Reneta Raykova for her list of crustal structure models and for discussions. We are grateful to: Gideon Lopes Cardozo, Edi Kissling and Annie Souriau for sending us their velocity models in electronic form. We thank an anonymous reviewer for their valuable comments that improved the article. An early version of this study [Douglas et al., 2005] was presented at the conference Earthquake Engineering in the 21st Century (EE-21C), Ohrid, Macedonia on 29th August 2005.

\section{References}

N. N. Ambraseys and J. Douglas. Near-field horizontal and vertical earthquake ground motions. Soil Dynamics and Earthquake Engineering, 23(1):1-18, 2003.

N. N. Ambraseys, J. Douglas, S. K. Sarma, and P. M. Smit. Equations for the estimation of strong ground motions from shallow crustal earthquakes using data from Europe and the Middle East: Horizontal peak ground acceleration and spectral acceleration. Bulletin of Earthquake Engineering, 3(1):1-53, 2005.

H. Aochi and R. Madariaga. The 1999 Imit, Turkey, earthquake: Nonplanar fault structure, 
dynamic rupture process, and strong ground motion. Bulletin of the Seismological Society of America, 93(3):1249-1266, 2003.

J. J. Bommer, J. Douglas, and F. O. Strasser. Style-of-faulting in ground-motion prediction equations. Bulletin of Earthquake Engineering, 1(2):171-203, 2003.

D. M. Boore and J. Boatwright. Average body-wave radiation coefficients. Bulletin of the Seismological Society of America, 74(5):1615-1621, Oct 1984.

D. M. Boore and W. B. Joyner. Site amplifications for generic rock sites. Bulletin of the Seismological Society of America, 87(2):327-341, Apr 1997.

K. W. Campbell. Empirical near-source attenuation relationships for horizontal and vertical components of peak ground acceleration, peak ground velocity, and pseudo-absolute acceleration response spectra. Seismological Research Letters, 68(1):154-179, Jan/Feb 1997.

G. Costa, G.F. Panza, P. Suhadolc, and F. Vaccari. Zoning of the Italian territory in terms of expected peak ground acceleration derived from complete synthetic seismograms. Journal of Applied Geophysics, 30(2):149-160, 1993. In: Geophysical Exploration in Areas of Complex Geology, Cassinis, R. and Helbig, K. and Panza, G. F. (ed).

J. Douglas. Earthquake ground motion estimation using strong-motion records: A review of equations for the estimation of peak ground acceleration and response spectral ordinates. Earth-Science Reviews, 61(1-2):43-104, 2003.

J. Douglas, H. Aochi, P. Suhadolc, and G. Costa. The importance of crustal structure in explaining the observed uncertainties in ground motion estimation. In Proceedings of Earthquake Engineering in the 21st Century (EE-21C), Aug 2005.

J. Douglas, P. Suhadolc, and G. Costa. On the incorporation of the effect of crustal structure into empirical strong ground motion estimation. Bulletin of Earthquake Engineering, 2(1): 75-99, 2004.

Z. J. Du, A. Michelini, and G. F. Panza. EurID: a regionalized 3-D seismological model of Europe. Physics of the Earth and Planetary Interiors, 105:31-62, 1998.

G. H. F. Gardner, L. W. Gardner, and A. R. Gregory. Formation velocity and density - The diagnostic basics for stratigraphic traps. Geophysics, 39(6):770-780, Dec 1974.

R. W. J. Graves. Simulating seismic wave propagation in 3D elastic media using staggeredgrid finite differences. Bulletin of the Seismological Society of America, 86(4):1091-1106, Aug 1996. 
G. Laske, A. Dziewonski, and G. Masters. The Reference Earth Model website. On Internet at: http://mahi.ucsd.edu/Gabi/rem.html, Jan 2005.

A. R. Levander. Fourth-order finite-difference P-SV seismograms. Geophysics, 53:1425-1436, 1988.

G. G. O. Lopes Cardozo. 3-D geophysical imaging and tectonic modelling of active tectonics of the upper Rhine graben region. PhD thesis, L'Université Louis Pasteur - Strasbourg I, 2003.

A. Martínez-Pereira and J. J. Bommer. What is the near-field? In E. Booth, editor, Proceedings of the Sixth SECED Conference on Seismic Design Practice into the Next Century, pages 245-252, Mar 1998.

K. B. Olsen. Simulation of three-dimensional wave propagation in the Salt Lake Basin. $\mathrm{PhD}$ thesis, University of Utah, 1994.

A. Souriau and M. Granet. A tomographic study of the lithosphere beneath the Pyrenees from local and teleseismic data. Journal of Geophysical Research, 100(B9):18117-18134, Sep 1995.

D. L. Wells and K. J. Coppersmith. New empirical relationships among magnitude, rupture length, rupture width, rupture area, and surface displacement. Bulletin of the Seismological Society of America, 84(4):974-1002, Aug 1994. 


\section{List of Figures}

1 Crustal structure models adopted for the three regions. . . . . . . . . . . . 12

2 Location of source and stations where ground motions are studied. The epicentre and stations are illustrated as a star and triangles, respectively. The form of the source-time function $(\mathrm{STF})$ is shown in the corner. . . . . . . . . . .

3 Comparison between the PGVs simulated for the Alpine structure for a $M_{w} 5.0$ earthquake at a depth of $5 \mathrm{~km}$ with different focal mechanisms. . . . . . . . . . 14

4 Comparison between the PGVs simulated for the Alpine structure for dip-slip $\left(\lambda=-90^{\circ}, \delta=45^{\circ}\right)$ earthquakes of $M_{w} 4.5,5.0$ and 5.5 at a depth of $10 \mathrm{~km} .$.

5 Comparison between the PGVs simulated for dip-slip $\left(\lambda=-90^{\circ}, \delta=45^{\circ}\right)$ earthquakes in all three structure at varying depths and those estimated by the GMEE of Campbell [1997] for a hard rock site for a $M_{w} 5.0$ strike-slip/normal earthquake (dotted line) . . . . . . . . . . . . . . . . .

6 Real-to-equivalent hypocentral distance mappings for the three regions for each of the three depths for a $M_{w} 5.0$ dip-slip $\left(\lambda=-90^{\circ}, \delta=45^{\circ}\right)$ earthquake. . . .

7 Standard deviations of the mean real-to-equivalent hypocentral distance mapping functions overall, within a region and for a focal depth with respect to distance, for $M_{w} 5.0$ and dip-slip $\left(\lambda=-90^{\circ}, \delta=45^{\circ}\right)$ faulting. . . . . . . . . 18 

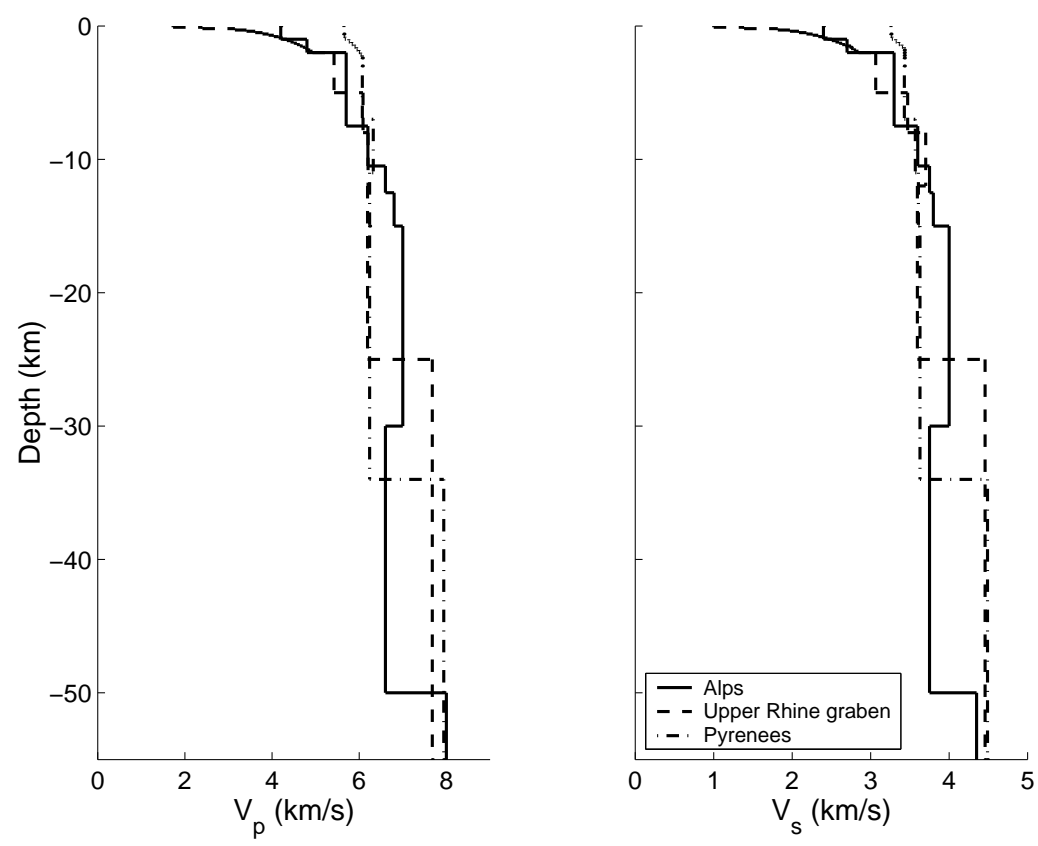

Figure 1: Crustal structure models adopted for the three regions. 


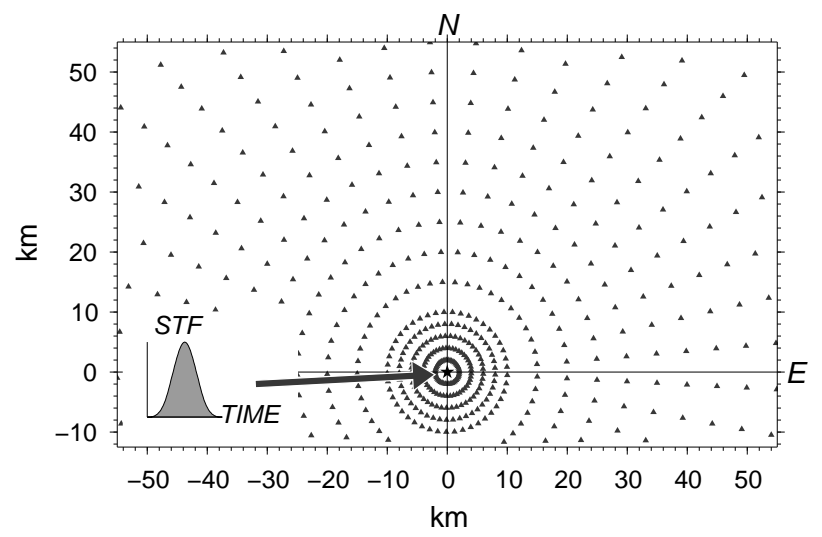

Figure 2: Location of source and stations where ground motions are studied. The epicentre and stations are illustrated as a star and triangles, respectively. The form of the source-time function (STF) is shown in the corner. 


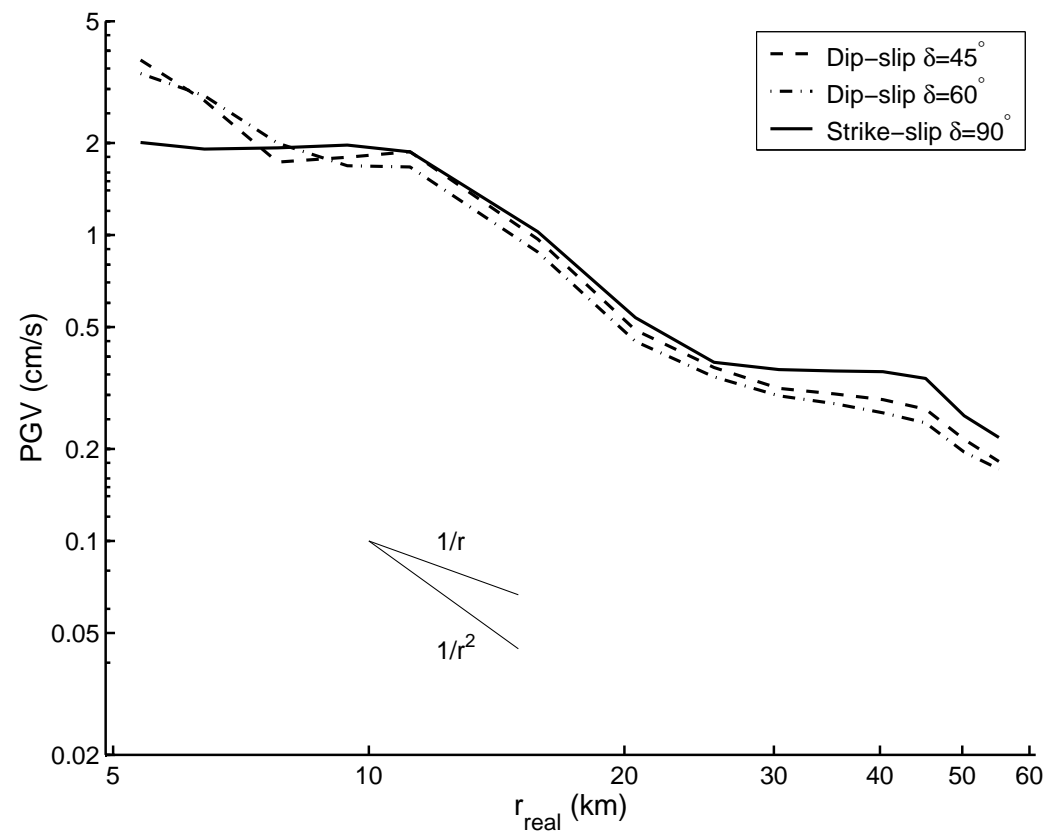

Figure 3: Comparison between the PGVs simulated for the Alpine structure for a $M_{w} 5.0$ earthquake at a depth of $5 \mathrm{~km}$ with different focal mechanisms. 


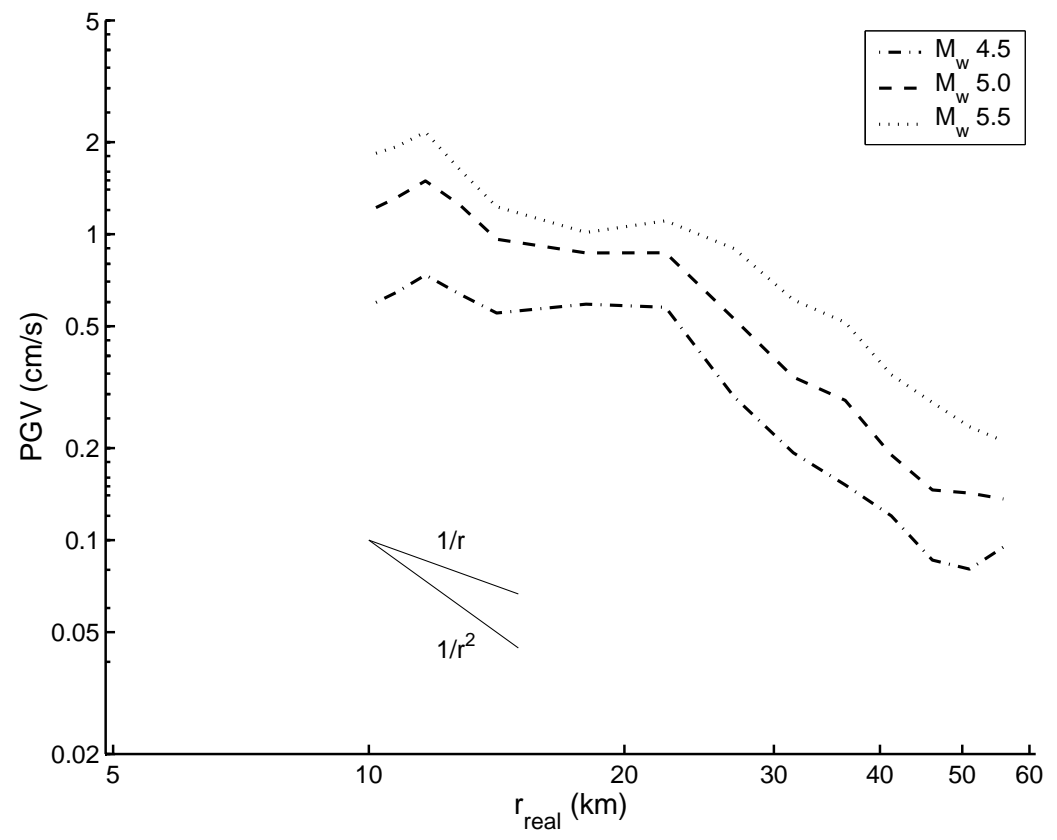

Figure 4: Comparison between the PGVs simulated for the Alpine structure for dip-slip $(\lambda=$ $-90^{\circ}, \delta=45^{\circ}$ ) earthquakes of $M_{w} 4.5,5.0$ and 5.5 at a depth of $10 \mathrm{~km}$. 


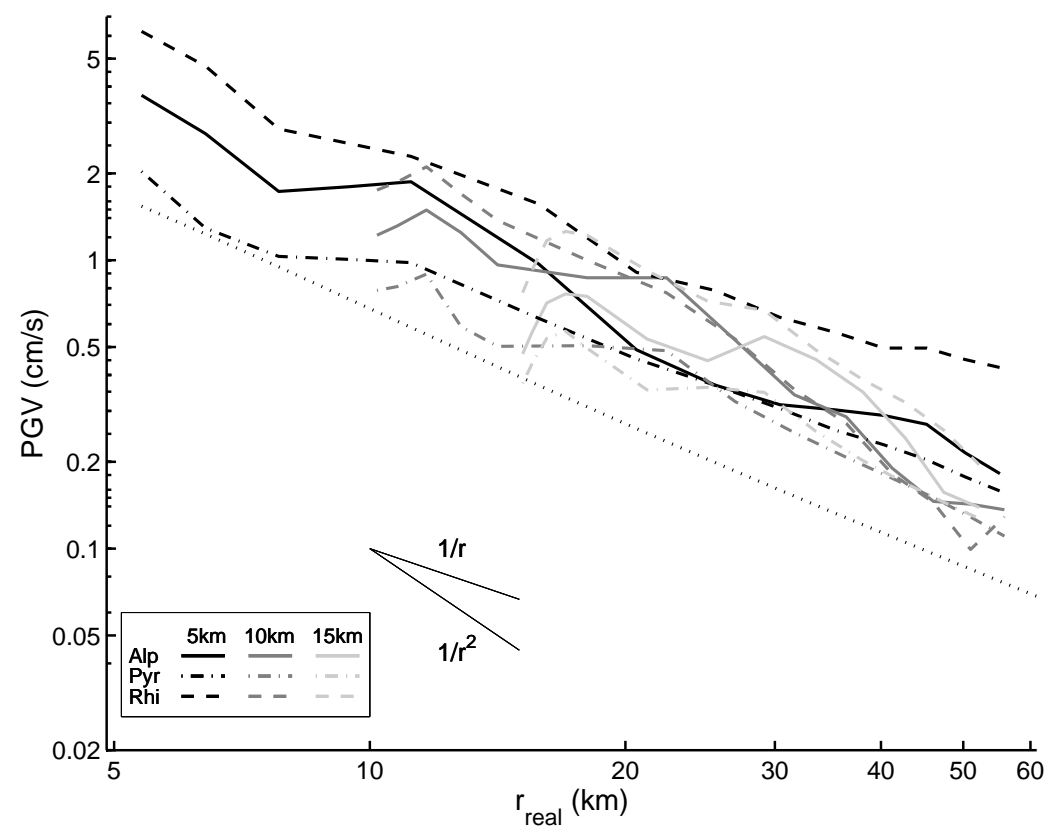

Figure 5: Comparison between the PGVs simulated for dip-slip $\left(\lambda=-90^{\circ}, \delta=45^{\circ}\right)$ earthquakes in all three structure at varying depths and those estimated by the GMEE of Campbell [1997] for a hard rock site for a $M_{w} 5.0$ strike-slip/normal earthquake (dotted line). 


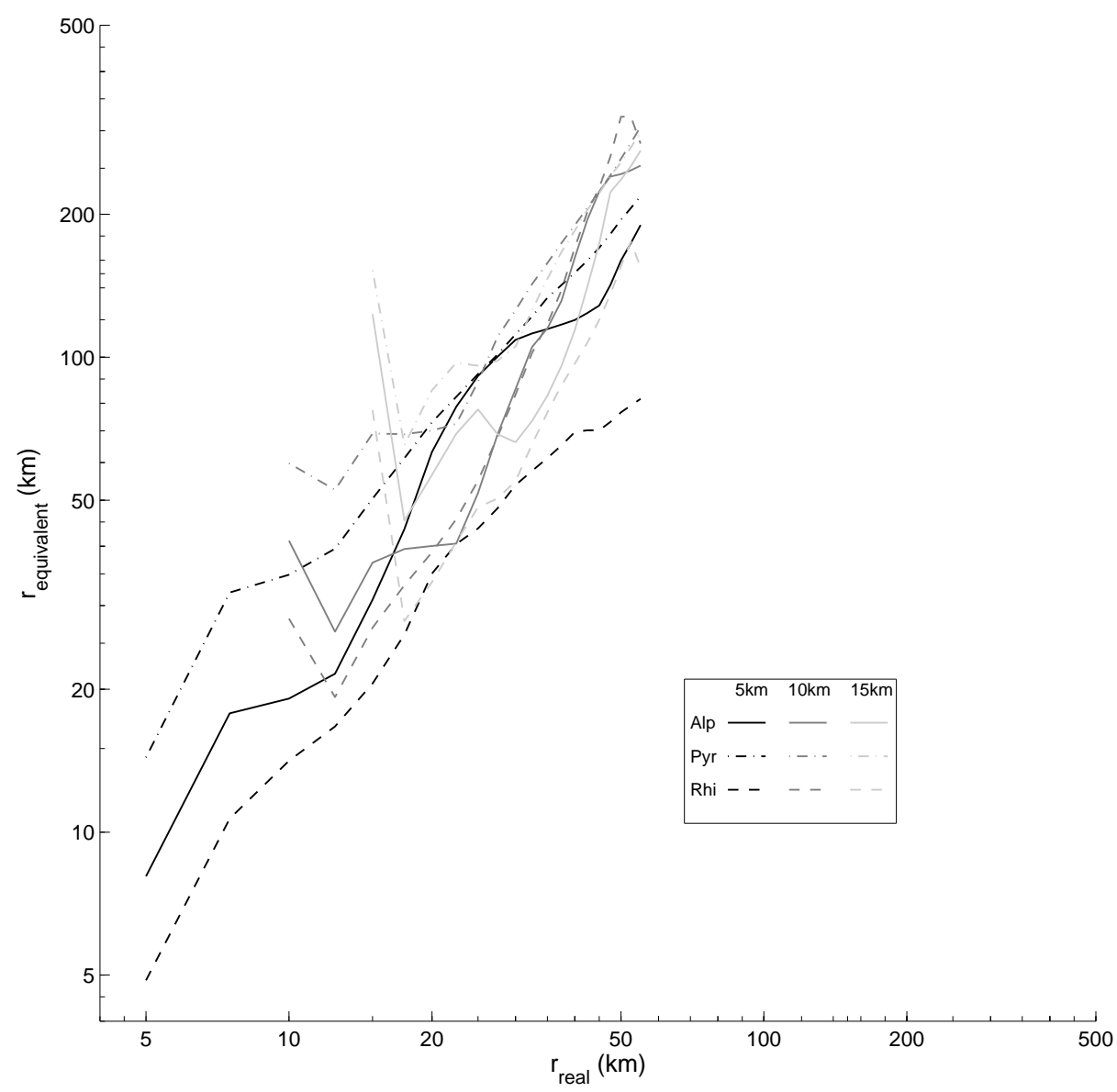

Figure 6: Real-to-equivalent hypocentral distance mappings for the three regions for each of the three depths for a $M_{w} 5.0$ dip-slip $\left(\lambda=-90^{\circ}, \delta=45^{\circ}\right)$ earthquake. 


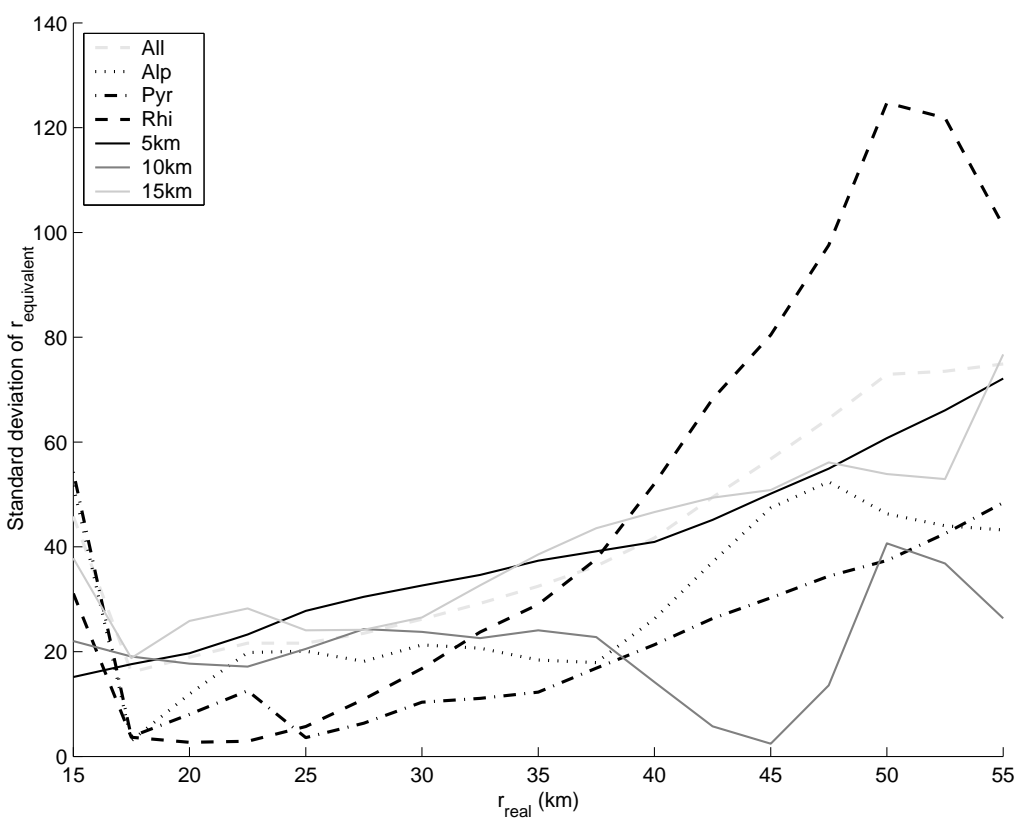

Figure 7: Standard deviations of the mean real-to-equivalent hypocentral distance mapping functions overall, within a region and for a focal depth with respect to distance, for $M_{w} 5.0$ and $\operatorname{dip}-\operatorname{slip}\left(\lambda=-90^{\circ}, \delta=45^{\circ}\right)$ faulting. 